Archives

$20 \mid 1998$

Miroirs de la Raison d'Etat

\title{
Note sur le théologico-politique
}

\section{Robert Descimon}

\section{(2) OpenEdition Journals}

\section{Édition électronique}

URL : http://journals.openedition.org/ccrh/2543

DOI : $10.4000 /$ ccrh. 2543

ISSN : $1760-7906$

\section{Éditeur}

Centre de recherches historiques - EHESS

\section{Édition imprimée}

Date de publication : 12 avril 1998

ISSN : 0990-9141

\section{Référence électronique}

Robert Descimon, « Note sur le théologico-politique », Les Cahiers du Centre de Recherches Historiques [En ligne], 20 | 1998, mis en ligne le 20 avril 2009, consulté le 21 avril 2019. URL : http:// journals.openedition.org/ccrh/2543; DOI : 10.4000/ccrh.2543

Ce document a été généré automatiquement le 21 avril 2019

Article L.111-1 du Code de la propriété intellectuelle. 


\title{
Note sur le théologico-politique
}

\author{
Robert Descimon
}

1 En une cinquantaine de pages, «L'État au miroir de la raison d'État» a déplacé une problématique fondatrice qui mobilise la science politique européenne de notre siècle, sinon du précédent. Depuis Kritik und Krise de Koselleck (1959) et Michel de Certeau (1982), on n'avait rien écrit de si fort sur la question. Cet exploit de Marcel Gauchet a été salué comme il méritait par les contributions subtiles, fortes, créatrices et même parfois polémiques de la présente table ronde.

2 L'ensemble ne laisse guère d'espace intellectuel à celui à qui avait été demandé de faire office de modérateur : tâche honorable, que seule l'amitié des organisateurs me donnait compétence à remplir. Aujourd'hui, je me contenterai de présenter une proposition lapidaire, je l'espère provocatrice et mal reçue de tous les acteurs.

3 «L'État est le concept en lequel se condense et culmine la nouveauté théologique du $\mathrm{XVI}^{\mathrm{e}}$ siècle ", écrit (p. 202) M. Gauchet. Mais cette nouveauté, avec l'apparition d'un concept qui ne saurait historiquement atteindre d'emblée son «déploiement complet et définitif ", n'est-ce pas précisément le théologico-politique lui-même? «Enjeu religieux du concept d'État »: Pierre de Belloy écrivait, dès 1585 : «La République n'est pas dans l'Église, mais, au contraire, l'Église est dans la République»; et, pulvérisant l'enseignement cardinal de seize siècles de christianisme catholique, ou, du moins, la structure anthropologique qui avait affirmé son hégémonie autour des ordres mendiants au XIII ${ }^{e}$ siècle, un anonyme allait jusqu'à écrire : «L'État n'est pas dans la religion, mais la religion dans l'État ». D'Église, il n'était déjà plus question. Quant à la religion, on en parle encore... Si se trouvent ainsi congédiées «les prétentions de l'Église à constituer l'intermédiaire obligatoire entre ici-bas et au-delà » (p. 210) et à créer le lien social dans le monde chrétien, il a bien fallu que le rapport à Dieu s'installât au cœur de ce nouveau principe de solidarité qu'était l'État. Le politique ne pouvait aller sans le théologique.

4 Avant, ce que nos interprétations herméneutiques lisent comme du "politique » n'était que du théologique. La pensée de la communauté humaine ne prenait source que dans Dieu. Les discussions sur son organisation passaient par le rapport à Dieu. Le politique était inclus dans le théologique, la république dans l'Église. Les lectures que nous 
proposons aujourd'hui de Jean de Salisbury ou de saint Thomas comme auteurs « politiques » sont donc anachroniques par leur non-contextualité.

Après, quand devient "pensable », au sens plein, l'idéologie des Lumières, qui s'incarne dans ce qu'on nommera assez malheureusement le «despotisme éclairé » (une lumière qui vient pour bonne part de la religion naturelle, mais aussi d'un agnosticisme), l'État n'a plus besoin de mettre au dessus de lui un Dieu qu'il avait déjà mené de l'immanence à la transcendance au sortir des guerres civiles de Religion. Avec le « déploiement complet et définitif du concept d'État ", la religion tend à affirmer sa dimension privée, même si elle ne perd jamais tout à fait un horizon de publicité. Elle n'est plus une "confession", orthodoxie garantie par l'État (idée que rend si bien le concept d'origine allemande de «confessionnalisation»). Le politique n'est plus indissociablement théologique. En somme, on serait passé de l'inclusion du politique dans le théologique à l'inclusion du théologique dans le politique, schéma qui est la simple traduction de la formule de Pierre de Belloy. Le troisième temps serait celui d'une indépendance réciproque, qui n'exclut pas les points de contact ou d'échange. Cela n'infirme pas la théorie schmittienne qui veut que « tous les concepts prégnants de la théorie moderne de l'État sont des concepts théologique sécularisés" (Théologie politique, p. 46 de la traduction française), mais renvoie cette proposition à une " conjoncture théologico-politique » éphémère qui prive de portée philosophique la parole de Carl Schmitt, un catholique en politique. Ce que Jean-François Courtine avait déjà dit.

6 L'âge théologico-politique serait alors une époque aussi brève que décisive, un siècle - le $\mathrm{XVII}^{\mathrm{e}}$-, suivi par un autre où l'arrimage systémique, mais impur, se défit progressivement, ouvrant la voie à d'autres anthropologies de la religion et de l'État. 